Revue

Revue de l'histoire des religions

de Ihistoire

des religions

3 | 2016

Varia

Tine van osselaer, The Pious Sex. Catholic

Constructions of Masculinity and Feminity in Belgium, c. $1800-1940$

Leuven, Leuven University Press, 2013

Matthieu Brejon de Lavergnée

\title{
OpenEdition
}

Journals

Édition électronique

URL : http://journals.openedition.org/rhr/8623

DOI : $10.4000 /$ rhr.8623

ISSN : 2105-2573

Éditeur

Armand Colin

Édition imprimée

Date de publication : 1 septembre 2016

Pagination : 462-465

ISBN : 978-2-200-93061-5

ISSN : 0035-1423

Référence électronique

Matthieu Brejon de Lavergnée, "Tine van osselaer, The Pious Sex. Catholic Constructions of Masculinity and Feminity in Belgium, c. 1800-1940", Revue de I'histoire des religions [En ligne], 3 | 2016, mis en ligne le 06 octobre 2016, consulté le 25 septembre 2020. URL : http://journals.openedition.org/rhr/8623 ; DOI : https://doi.org/10.4000/rhr.8623

Ce document a été généré automatiquement le 25 septembre 2020.

Tous droits réservés 


\section{Tine VAN OSSELAER, The Pious Sex. Catholic Constructions of Masculinity and Feminity in Belgium, c. 1800-1940}

Leuven, Leuven University Press, 2013

Matthieu Brejon de Lavergnée

\section{RÉFÉRENCE}

Tine VAN OSSELAER, The Pious Sex. Catholic Constructions of Masculinity and Feminity in Belgium, c. 1800-1940, Leuven, Leuven University Press, 2013, 272 p., 23,5 cm, 45,50 €, ISBN 978-90-5867-950-5.

1 Issu d'un PhD soutenu à l'université de Leuven (Belgique), cet ouvrage offre une remarquable démonstration de l'intérêt du genre comme catégorie d'analyse pour le religieux. Mais plutôt que de traiter séparément de l'histoire des femmes et des hommes, l'auteur s'emploie à étudier conjointement les constructions catholiques de la féminité et de la masculinité.

2 Tine Van Osselaer entreprend tout d'abord une déconstruction de la thèse de la féminisation du catholicisme, bien connue du lecteur français depuis la grande thèse de Claude Langlois sur Le Catholicisme au féminin (1984) selon laquelle le xIX siècle aurait connu une féminisation de la pratique, des dévotions et du personnel religieux. En réalité, cette thèse fonctionne de pair avec celle de la sécularisation, qui suppose non seulement une déperdition du religieux mais un rapatriement de ce qu'il en reste dans la sphère privée/féminine opposée à la sphère publique/masculine. Bien qu'elle ait eu le mérite d'introduire une réflexion genrée en histoire religieuse, cette double thèse est désormais détricotée de tous côtés par les travaux qui s'intéressent d'une part à l'engagement des femmes dans la sphère publique, au nom de leur foi, contribuant à la définition d'une citoyenneté avant le vote (Bruno Dumons, Magali Della Sudda), mais aussi par les recherches qui témoignent du réinvestissement de rôles religieux 
domestiques par les hommes, objet d'un ouvrage collectif récemment dirigé par Tine Van Osselaer et Patrick Pasture (Christian homes, Leuven University Press, 2014).

3 Mais la déconstruction va plus loin encore car l'auteur montre que les termes même de "féminisation" et son pendant "masculinisation", ainsi que leurs dérivés piété/ dévotion/ pratique «féminine » et "masculine » sont sujets à caution. Empruntés au vocabulaire indigène, ils sont en fait saturés de sens et contaminent le vocabulaire scientifique, ainsi de la dévotion au Sacré-Cœur sur laquelle s'appuie l'essentiel de l'ouvrage tour à tour perçue par les acteurs eux-mêmes comme féminine (une religion du sentiment) ou virile (le Christ, figure masculine) par opposition au culte marial, ou encore l'expression " prêtre de la famille » associée au pater familias dans les sermons mais aussi bien à la mère, voire au couple.

Les significations religieuses associées aux sexes ne cessent en fait d'évoluer. La caricature anticléricale mais aussi les manuels destinés au clergé définissent au XIX siècle les femmes comme le "sexe pieux ", cette naturalisation du sentiment religieux étant renforcée à la fin du siècle par la littérature médicale. Les manuels étudiés par l'auteur révèlent toutefois un rapport ambivalent aux femmes (piété mal réglée, prudence nécessaire face à leurs envahissements) tandis qu'ils appellent au contraire à prendre particulièrement soin des hommes tenus à distance de l'Église par le respect humain (le regard de leurs pairs). Cette construction des hommes comme "sexe pieux" connaît une inflation fin $\mathrm{XIX}^{\mathrm{e}}$-début $\mathrm{Xx}^{\mathrm{e}}$ siècle, renforcée dans l'entre-deux-guerres par un appel à la virilité du prêtre. Le contexte belge - des comparaisons sont avancées avec d'autres pays et d'autres confessions (cf. Muscular christianity, Männerapostolat) expliquerait cette attention soutenue aux hommes. À l'heure des tensions entre catholiques et libéraux, en particulier la guerre scolaire (1879-1884), mais aussi face à la séduction du socialisme sur les ouvriers, l'Église a besoin de renforcer ses bastions en s'assurant du soutien des hommes: vote pour les candidats catholiques, envoi des enfants dans les écoles catholiques. Dans le même temps, le clergé valorise la piété domestique masculine, voyant dans une paternité bien assumée la condition d'une société stable. Le règne privé $d u$ père favorise le règne public de Dieu. Les sphères apparaissent ainsi comme poreuses dans les représentations du clergé.

On pourrait reprocher à l'auteur de ne s'appuyer que sur des sources narratives et normatives (manuels, sermons, périodiques) qui auraient gagné à être complétées par des ego-documents (journal intime, correspondance). Ceux-ci permettent d'entrer dans les représentations des laïcs et non des seuls clercs et d'envisager leur consentement ou la négociation face à ces rôles imposés, approche qui a fait ses preuves dans ce qui relève de l'intime, ainsi de la sexualité (Martine Sevregand) ou de la direction de conscience (Caroline Muller). C'est ce que corrigent les deux études de cas qui, après un chapitre sur le regard clérical porté sur l'ensemble des fidèles ("Good catholics »), s'attachent aux élites ferventes ("Devoted catholics»). Celles-ci sont appréhendées à travers les ligues du Sacré-Cœur et les mouvements d'Action catholique dont les archives sont conservées par les diocèses belges ou celles du KADOC à Leuven où les archives jésuites ont été versées.

6 L'Apostolat de la prière, association de laïcs fondée par un jésuite français dans les années 1840, est importé en Belgique vingt ans plus tard. Le mouvement demeure mixte mais le bureau central devient exclusivement féminin sous la houlette du P. Toussaint Dufau. C'est peut-être une des raisons des difficultés de l'association à s'implanter dans les paroisses - outre l'opposition traditionnelle mouvements/ 
paroisses - bien que le clergé apprécie ses vertus sur les hommes. On le perçoit mieux encore à partir des années 1890 quand la revue du mouvement (Le Messager du SacréCœur de Jésus) tente de masculiniser ses troupes et crée, pour les ouvriers initialement qu'il faut arracher au socialisme, pour tous ensuite, des retraites pour hommes prolongées par les ligues du Sacré-Cœur. Le clergé diocésain, qui partage les mêmes préoccupations, fait alors un excellent accueil aux ligues d'autant que la répartition des rôles fait une place à chacun : l'organisation centrale aux jésuites, l'administration locale aux curés, les activités du mouvement aux hommes laïcs. Le ton se masculinise. D'individuelle, la dévotion au Sacré-Cœur devient plus collective à travers les communions mensuelles. Dans les années 1930, à l'unisson de tous les mouvements, confesssionnels ou non, les ligues privilégient démonstrations de masse, consécration publique des drapeaux, campagnes d'opinion («Back to the Sunday mass»). Les femmes ne sont pas en reste, encourageant leur mari à rejoindre les ligues mais créant aussi les leurs car les hommes supportent mal leur présence au sein de leurs nouveaux espaces de sociabilité religieuse. C'est ainsi qu'un mouvement mixte s'est progressivement divisé en branches féminine et masculine. Toutefois, ces pratiques genrées ne se retrouvent pas dans le discours où l'appel à l'héroïsme chrétien use souvent de figures ambiguës : la femme forte, voire martiale comme Jeanne d'Arc; les souffrances et les larmes du martyr, telles celles des zouaves pontificaux. Les modèles de sainteté paraissent ainsi peu genrés (le courage est proposé aux femmes comme aux hommes) par rapport aux pratiques (séparation nette des mouvements) révélant, au sein d'une Église saturée de genre, une «zone grise » où les frontières de genre sont aisément franchies.

7 Ainsi, au couple trop convenu femme pieuse/mari anticlérical, à tout le moins détaché, Tine Van Osselaer substitue une réalité plus complexe où le «sexe pieux » est aussi, nullement par nature mais bien par construction, de genre masculin. Il resterait à emprunter cette piste jusqu'à observer des fronts renversés, comme Paul Chopelin qui pointe le couple militantes constitutionnelles/militants réfractaires sous la Révolution française, là où l'on associe trop souvent les femmes à la seule Église réfractaire (in Genre et Christianisme. Plaidoyers pour une histoire croisée, Beauchesne, 2014). Cette dernière perspective, partagée par le clergé du début du xix siècle, a pu susciter en retour une féminisation du catholicisme, les femmes paraissant de plus sûrs soutiens pour rebâtir l'Église par les tâches éducatives, soignantes et charitables. Où l'on retrouve la «feminisation thesis » dont on n'a pas fini de discuter.

\section{AUTEURS}

\section{MATTHIEU BREJON DE LAVERGNÉE}

Université Paris-Sorbonne. 